\title{
Gall bladder contractility in neonates: effects of parenteral and enteral feeding
}

\author{
G Jawaheer, A Pierro, D A Lloyd, N J Shaw
}

\begin{abstract}
The gall bladder size was measured in 30 newborn infants: 18 had been fed parenterally and 12 enterally. The two groups were comparable for gestational age, birthweight, postnatal age and study weight. Exclusion criteria were haemodynamic instability, septicaemia, abdominal disease and opioid treatment. Gall bladder size was measured at $\mathbf{1 5}$ minute intervals for $\mathbf{9 0}$ minutes using real-time ultrasonography and the volume calculated using the ellipsoid method. Parenterally fed infants had further measurements at 120, 150, and 360 minutes. The gall bladder was significantly larger in parenterally fed infants than in enterally fed infants $(p=0 \cdot 0001)$. In enterally fed infants a $50 \%$ reduction in gall bladder volume was observed 15 minutes after starting the feed with a return to baseline volume by 90 minutes. In parenterally fed infants there was no gall bladder contraction.

Such information may give insight into the pathophysiology of hepato-biliary complications during parenteral nutrition in infants.
\end{abstract}

(Arch Dis Child 1995; 72: F200-F202)

Keywords: gall bladder, neonates, parenteral, enteral.

The advent of parenteral nutrition has permitted the long term survival of infants with intestinal failure. Cholestasis is the major complication of parenteral nutrition in these infants and ultimately leads to liver failure. ${ }^{1}$ The pathophysiology of this condition is poorly understood. Gall bladder stasis has been observed in adults receiving continuous parenteral feeding. ${ }^{2}$ This is associated with the accumulation of sludge in the gall bladder and may be a contributing factor to the development of cholestasis. To our knowledge, gall bladder contractility has not been investigated in neonates receiving parenteral nutrition. The aim of this study was to investigate the effects of continuous parenteral feeding and bolus enteral feeding on gall bladder contractility in newborn infants.

\section{Methods}

Two groups of newborn infants were studied: 18 infants receiving parenteral feeding and 12 infants receiving enteral feeding. Both groups included preterm and term infants. No infant received combined parenteral and enteral nutrition. Exclusion criteria for the study were septicaemia, use of opioids, ${ }^{3}$ haemodynamic instability and evidence of abdominal pathology.
Indications for parenteral nutrition were respiratory distress and intolerance of enteral feeding. Parenteral nutrients were administered continuously by precision infusion pumps (Neo.Mate IVAC 565, San Diego, California, USA). Enteral feeds were given as a bolus orally or by nasogastric tube every two to four hours. Parenteral nutrients were either carbohydrate (10\% dextrose) $(n=5)$; carbohydrate and amino acids (Vamin-9-Glucose, Pharmacia, Milton Keynes, UK) $(\mathrm{n}=8)$; or carbohydrate, amino acids and fat (Intralipid 20\%, Pharmacia, Milton Keynes) $(n=5)$. The last two parenteral diets also included vitamins and trace elements. All parenteral solutions contained electrolytes. Enteral diets included expressed breast milk or formula milk, or both. Parenteral and enteral caloric intakes were not standardised.

Informed consent was obtained from parents and the study protocol was approved by the ethics committees of Fazakerley and Alder Hey Children's hospitals.

Gall bladder volume was measured by a single investigator (GJ), using a real-time ultrasound machine (Ultramark 4 Plus, Advanced Technology Laboratories, Bothell, USA), with a $5 \mathrm{MHz}$ transducer. The maximum length, width, and height of the gall bladder were measured in millimetres. Each parameter was measured three times consecutively and the mean maximum length, width, and height calculated. Intra-observer error was estimated. For each group, the standard error of the mean length, width, and height was calculated from the three sets of measurements for each parameter. The standard error of the mean length, width, and height was $0.1 \mathrm{~mm}, 0.2 \mathrm{~mm}$, and $0.1 \mathrm{~mm}$, respectively, for the parenterally fed, and $0.2 \mathrm{~mm}, 0.1$, and $0.2 \mathrm{~mm}$, respectively, for the enterally fed infants. Gall bladder volume $\left(\mathrm{mm}^{3}\right)$ was calculated using the ellipsoid formula ${ }^{4}$ :

Gall bladder volume $\left(\mathrm{mm}^{3}\right)$

$=\pi \times$ maximum length $(\mathrm{mm})=\pi \times$ maximum width $(\mathrm{mm})$ $=\pi \times$ maximum height $(\mathrm{mm})$

6

In patients receiving parenteral feeding, gall bladder volume was measured randomly (baseline volume) and subsequently after $15,30,45$, $60,90,120,150$, and 360 minutes. In enterally fed infants gall bladder volume was measured immediately before feeding (baseline volume) and subsequently $15,30,45,60$, and 90 minutes after the start of feeding. The gall bladder contraction index was calculated as follows:

baseline volumeminimum postprandial volume

Contraction index $=\longrightarrow \times 100$

baseline volume 
STATISTICAL ANALYSIS

Data are expressed as median and interquartile range. Absolute gall bladder volumes, rather than percentage changes, were compared. Comparisons between the groups were made using the Mann-Whitney U test. Comparisons of gall bladder volume within the groups were made using the Wilcoxon matched pairs signed rank test. Differences were regarded as significant at $p<0.05$. The data were analysed using the SPSS-PC+ V 3.1 program (Microsoft Corporation, Chicago, USA).

\section{Results}

There was no significant difference between the two groups with respect to gestational age, birthweight, postnatal age, weight at the time of the study, duration of the respective diet and fluid intake (table). Enterally fed infants received a higher caloric intake than infants fed parenterally (table). Parenteral caloric intake ( $\mathrm{kcal} / \mathrm{kg} /$ day) for infants who received only carbohydrate was $33.8(25 \cdot 3-41 \cdot 8)$, for infants who received carbohydrate and amino acids this was $64.6(44 \cdot 6-71 \cdot 4)$, and for infants who received carbohydrate, amino acids and fat this was $75 \cdot 2(69 \cdot 7-96 \cdot 4)$.

Baseline gall bladder volume was higher in parenterally fed infants $(926 \cdot 4(626 \cdot 3-1462 \cdot 0)$ $\mathrm{mm}^{3}$ ) than in enterally fed infants $(240 \cdot 1$ (159.9-594.9) $\mathrm{mm}^{3} ; \mathrm{p}=0.0001$ ) (fig 1). There was no difference in baseline gall bladder volume among infants receiving the three types of parenteral diet (fig 1). In all parenterally fed infants there was no gall bladder contraction (fig 2). In all enterally fed infants the gall bladder contracted 15 minutes after the bolus feed and returned to baseline volume by 90 minutes (fig 2). The median contraction index was $49 \cdot 5 \%(38 \cdot 3-61 \cdot 7)$. In the enterally fed infants there was no correlation between caloric intake and contraction index $(r=0.04$; $\mathrm{p}=0.91$ ).

\section{Discussion}

Little is known about the characteristics of gall bladder contractility in newborn infants. Studies in adults, using ultrasonography, have shown that the gall bladder contracts after a meal ${ }^{4-6}$ and becomes more than half empty 15 minutes after ingestion of a fatty meal. ${ }^{5}$ Maximal gall bladder contraction is reached from 30 minutes $^{45}$ to 110 minutes $^{6}$ and varies from $63 \%{ }^{4}$ to $80 \% .{ }^{5}$ It is not known when the gall bladder returns to baseline volume in adults. Two studies of gall bladder contractility in preterm infants have been made. ${ }^{78}$

Clinical data (median and range)

\begin{tabular}{lccc}
\hline & $\begin{array}{c}\text { Parenteral feeding } \\
(n=18)\end{array}$ & $\begin{array}{l}\text { Enteral feeding } \\
(n=12)\end{array}$ & $\begin{array}{c}p \\
\text { Value }\end{array}$ \\
\hline Gestational age (weeks) & $30 \cdot 0(28 \cdot 8-34 \cdot 3)$ & $32 \cdot 5(32 \cdot 0-34 \cdot 8)$ & $0 \cdot 11$ \\
Birthweight (kg) & $1 \cdot 5(0 \cdot 9-2 \cdot 3)$ & $1 \cdot 8(1 \cdot 7-2 \cdot 3)$ & $0 \cdot 16$ \\
Postnatal age (days) & $5 \cdot 0(2 \cdot 8-5 \cdot 3)$ & $8 \cdot 0(3 \cdot 3-9 \cdot 8)$ & $0 \cdot 13$ \\
Study weight (kg) & $1 \cdot 3(0 \cdot 8-2 \cdot 3)$ & $1 \cdot 8(1 \cdot 7-2 \cdot 2)$ & $0 \cdot 20$ \\
Duration of diet (days) & $5 \cdot 0(2 \cdot 8-5 \cdot 3)$ & $5 \cdot 5(2 \cdot 3-7 \cdot 8)$ & $0 \cdot 52$ \\
Fluid intake (m1/kg/day) & $156 \cdot 5(97 \cdot 0-190 \cdot 1)$ & $164 \cdot 7(147 \cdot 4-180 \cdot 0)$ & $0 \cdot 64$ \\
Caloric intake (kcal/kg/day) & $64 \cdot 6(36 \cdot 3-72 \cdot 7)$ & $109 \cdot 5(95 \cdot 5-132 \cdot 2)$ & $0 \cdot 0004$ \\
\hline
\end{tabular}

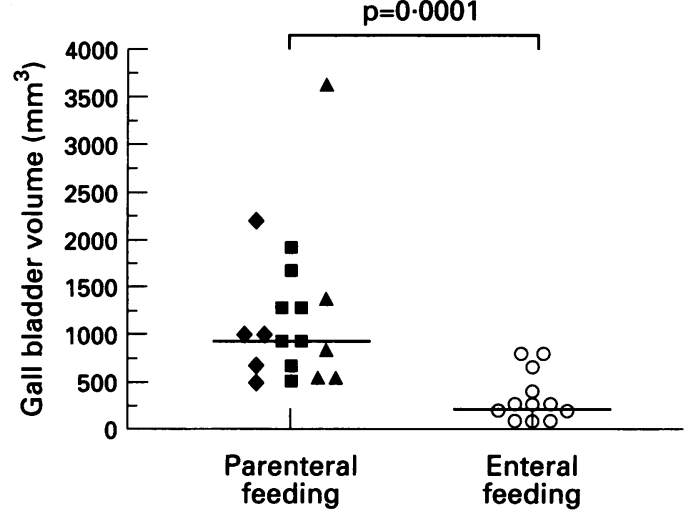

Figure 1 Gall bladder volume at baseline. The gall bladder was larger in the parenterally fed infants, irrespective of the composition of their parenteral diet. $\checkmark=$ carbohydrate; $\nabla=$ carbohydrate + amino acids;

$\Delta=$ carbohydrate + amino acids + fat .

However, the gall bladder was not studied during the first hour after the meal, thereby missing any possible contraction during this period. To our knowledge, our study shows for the first time that the gall bladder of enterally fed infants contracts within 15 minutes after a bolus feed and returns to baseline volume by 90 minutes.

The maximal gall bladder contraction index is lower in infants $(49.5 \%)$ than that reported in adults $(63 \%) .{ }^{4}$ The mechanism of this contraction in newborn infants is not known, but the most likely stimulus is the hormone cholecystokinin. In adults given a fatty meal plasma cholecystokinin concentrations start to rise as early as 10 minutes after the meal, reaching a peak at 20 minutes. ${ }^{5}$

A distended gall bladder has been observed in neonates receiving parenteral nutrition. ${ }^{910}$ However, dynamic studies of gall bladder contractility during parenteral nutrition have not been carried out in newborn infants. In this study the gall bladder volume was measured over six hours and it was assumed that gall bladder volume during this period was representative of the volume of the gall bladder
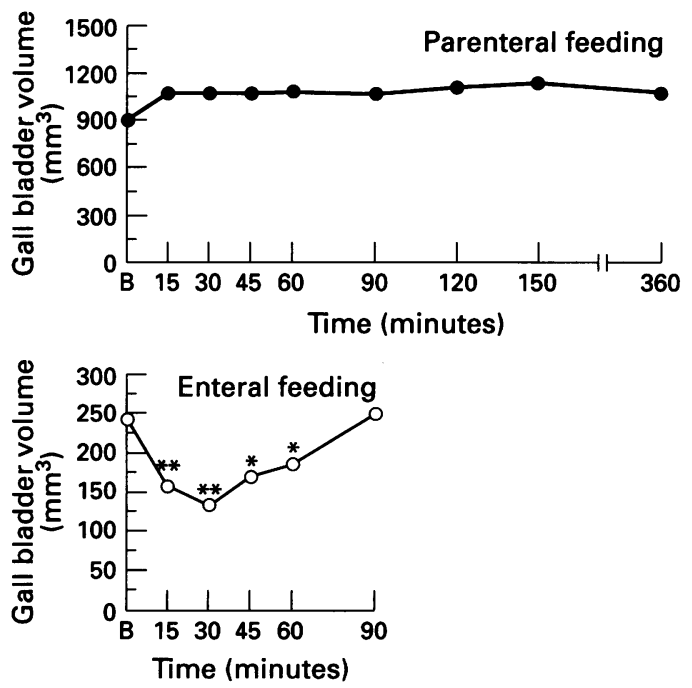

Figure 2 Gall bladder response to parenteral and enteral feeding. Gall bladder contraction is observed only in enterally fed infants. Maximal gall bladder contraction is observed at 30 minutes. Gall bladder volume returns to baseline by 90 minutes. ${ }^{\star}=p<0 \cdot 005 ;{ }^{\star}=p<0.05$. 
throughout the course of parenteral nutrition. Our results are twofold: the gall bladder of parenterally fed infants does not contract (fig 2) and its volume is almost four times that of enterally fed infants (fig 1 ).

Possible factors contributing to these observations include differences in the caloric intakes, the composition of the diets, and the mode of delivery of nutrients. The parenterally fed infants received less calories than their enteral counterparts and their caloric intake varied according to the type of parenteral diet. Gall bladder contractility, however, did not vary within this group. Similarly, in the enterally fed infants, there was no correlation between caloric intake and gall bladder contraction index. Therefore, it seems unlikely that the difference in caloric intake accounts for the observed differences in gall bladder volume and contractility between the two groups.

Enteral fat, protein, and amino acids are the most potent stimulants of cholecystokinin secretion; oral glucose exerts a more transient and less potent effect. ${ }^{11}$ Intravenous glucose, amino acids, and fat theoretically have different effects on cholecystokinin secretion and gall bladder contractility. ${ }^{11}$ In this study the gall bladder of parenterally fed infants did not contract, irrespective of whether carbohydrate was given alone or in combination with amino acids and fat (fig 1). All parenterally fed infants received glucose; it was not feasible to investigate the effect of a carbohydrate-free parenteral diet on gall bladder contractility because of the risk of hypoglycaemia. It has been shown, however, in adults that blood glucose modulates gall bladder motility ${ }^{12}$ and that during parenteral infusion of glucose, the intraduodenal bile output induced by food is significantly decreased, suggesting that gall bladder contraction is impaired by a glucose infusion. ${ }^{13}$

The method of delivering the nutrients may have an important role in modulating gall bladder motility. In our study parenterally fed infants did not receive simultaneous enteral feeds. Therefore, the behaviour of the gall bladder in this group of infants might have been caused by the lack of enteral stimulation rather than the parenteral nutrition itself. Furthermore, in adults a continuous infusion of parenteral nutrients impairs gall bladder contraction $^{2}$ whereas bolus administration of parenteral amino acids promotes gall bladder motility. ${ }^{14}$ Further studies are needed to investigate the effects of combined parenteral and enteral feeding as well as bolus parenteral feeding on gall bladder contractility in newborn infants.

1 Quigley EMM, Marsh MN, Shaffer JL, Markin RS Hepatobiliary complications of total parenteral nutrition. Gastroenterology 1993; 104: 286-301.

2 Cano N, Cicero F, Ranieri F, Martin J, Di Costanzo J. Ultrasonographic study of gallbladder motility during total parenteral nutrition. Gastroenterology 1986; 91: 313-7.

3 Malave A, Yim GKW. Effects of chronic morphine on biliary tract responses to cholecystokinin-octapeptide in male guinea-pigs. Life Sci 1992; 51: 513-7.

4 Dodds WJ, Groh WJ, Darweesh RMA, Lawson TL, Kishk SMA, Kern MK. Sonographic measurement of gallbladder volume. Am $\mathcal{F}$ Radiol 1985; 145: 1009-11.

5 Nealon WH, Upp JR, Alexander RW, Gomez G, Townsend Jr CM, Thompson JC. Intravenous aminoacids stimulate human gallbladder emptying and hormone release. $A m \mathcal{F}$ Physiol 1990; 259: G173-8.

6 Okano H, Saeki S, Inui A, Kawai Y, Ohno S, Morimoto S, et al. Effect of trimebutine maleate on emptying of stomach and gallbladder and release of gut peptide following a solid meal in man. Dig Dis Sci 1993; 38: 817-23.

7 Lehtonen L, Svedstrom E, Korvenranta H. The size and contractility of the gallbladder in infants. Pediatr Radio 1992; 22: 515-8.

8 Lehtonen L, Svedstrom E, Kero P, Korvenranta H Gallbladder contractility in preterm infants. Arch Dis Child 1993; 68: 43-5.

9 Barth RA, Brasch RC, Filly RA. Abdominal pseudotumor in childhood: distended gallbladder with parenteral hyperalimentation. Am F Radiol 1981; 136: 341-3.

10 Arad I, Peleg O, Udassin R, Zamir O, Goldberg M, Lebensart P. Gallbladder distension in premature neonates
receiving parenteral nutrition. $\mathcal{F}$ Perinat Med 1989; 17: 337.

11 Liddle RA, Goldfine ID, Rosen MS, Taplitz RA, Williams JA. Cholecystokinin bioactivity in human plasma. $\mathcal{f}$ Clin JA. Cholecystokinin bioact

12 De Boer SY, Masclee AAM, Lam WF, Schipper J, Lamers CBHW. Blood glucose modulates gallbladder motility and small intestinal transit time. Gastroenterology 1992 102: A549.

13 MacGregor IL, Deveney C, Way LW, Meyer JH. The effect of acute hyperglycaemia on meal-stimulated gastric, biliary and pancreatic secretion and serum gastrin Gastroenterology 1976; 70: 197-202.

14 Zoli G, Ballinger A, Healy J, O'Donnell LJD, Clark M, Farthing MJG. Promotion of gallbladder emptying by intravenous aminoacids. Lancet 1993; 341: 1240-1. 